\title{
STRATEGI PEMASARAN
}

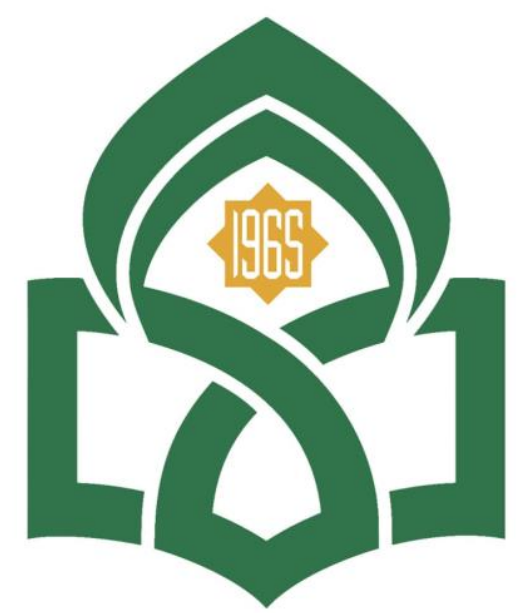

UNIVERSITAS ISLAM NEGERI

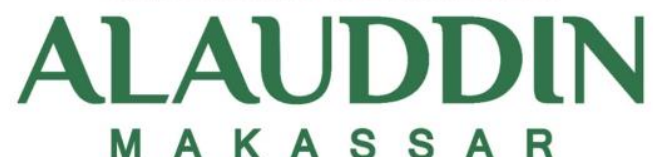

M A K A S S A R

Dosen Pengampuh:

Dra. Hj. Nuraeni Gani, M.M

Disusun Oleh:

Rahmadana

90500120025

PERBANKAN SYARIAH

FAKULTAS EKONOMI DAN BISNIS ISLAM

UNIVERSITAS ISLAM NEGERI ALAUDDIN MAKASSAR

$2021 / 2022$ 


\section{KATA PENGANTAR}

Puji syukur kami panjatkan kehadirat Tuhan yang Maha Esa. Atas rahmat dan hidayahNya, penulis bisa menyelesaikan makalah studi kelayakan bisnis yang berjudul "Strategi Pemasaran".

Tak lupa penulis mengucapkan terimah kasih kepada semua pihak yang telah membantu dan berkontribusi dalam menyelesaikan makalah ini.

Penulis menyadari ada kekurangan pada penulisan makalah ini. Oleh sebab itu, saran dan kritik senantiasa diharapkan demi perbaikan karya penulis. Penulis juga berharap semoga makalah ini mampu memberikan pengetahuan kepada khalayak luas.

Gowa, 01 Desember 2021

Penulis 


\section{DAFTAR ISI}

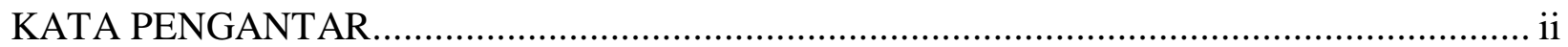

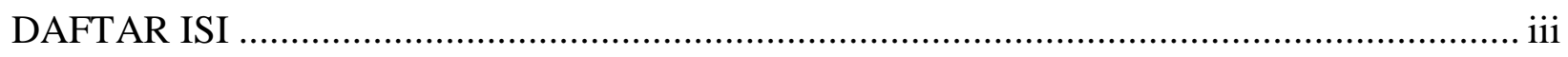

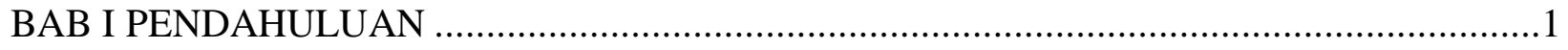

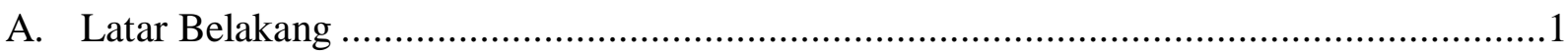

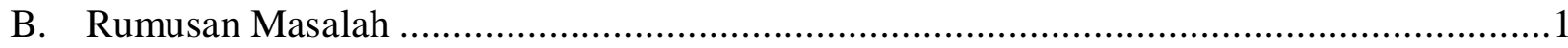

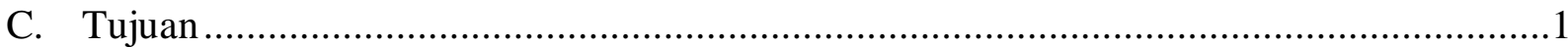

BAB II PEMBAHASAN ..........................................................................................

A. Pengertian Strategi dan Pemasaran .................................................................

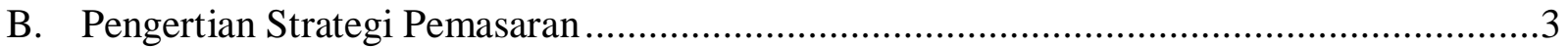

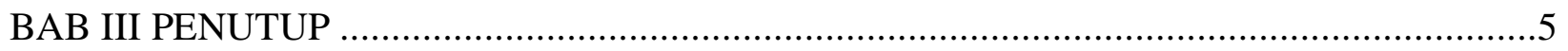

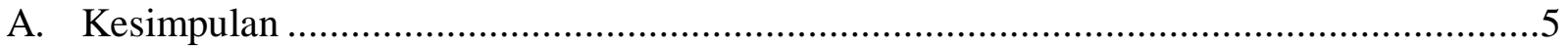

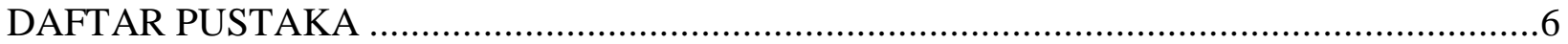




\section{BAB I}

\section{PENDAHULUAN}

\section{A. Latar Belakang}

Di indonesa banyak sekali perusahaan atau lembaga yang bersaing dengan beragam inovasi untuk mengembangkan usahanya agar lebih maju. Dalam suatu perusahaan dibutuhkan banyak pertimbangan untuk keuntungan dan proft yang didapatkan lebih banyak daripada modal yang dikeluarkan namun dengan kualitas yang terjamin.

Pasar merupakan tempat bertemunya penjual dan pembeli untuk melakukan transaksi. Dalam studi kelayakan bisnis aspek pasar merupakan aspek yang berkaitan dengan kondisi pasar dari bidang industri yang dijalankan oleh sebuah bisnis, yang dianalisa biasanya akan meliputi permintaan pasar tehadap produk yang akan dijual, tingkat persaingan dan strategi pesaing dalam memasarkan produk, dan segmentasi pasar. Aspek pasar dan pemasaran menjadi hal penting yang perlu diperhatikan dalam studi kelayakan bisnis, karena aspek tersebut nantinya dapat membantu sebuah bisnis utnuk menentukan arah dan tujuan serta sasaran pemasaran dari produk yang akan ditawarkan.

\section{B. Rumusan Masalah}

Adapun rumusan masalah dari makalah ini yaitu apa yang yang dimaksud dengan strategi pemasaran?

\section{Tujuan}

Dari rumusan masalah diatas didapatkan tujuan dari makalah ini, yaitu untuk mengetahui strategi pemasaran. 


\section{BAB II \\ PEMBAHASAN}

\section{A. Pengertian Strategi dan Pemasaran}

Strategi adalah keseluruhan konsep bagaimana sebuah perusahaan mengatur dirinya sendiri dan semua kegiatan dengan tujuan agar bisnis yang dijalankan berhasil, melakukan persaingan, dan melakukan imbal hasil kepada pemegang saham.

Pemasaran merupakan serangkaian kegiatan mulai dari proses dalam pembuatan, mengkomunikasikan mengenalkan dan menawarkan transaksi yang mempunyai nilai bagi konsumen, klien, partner, dan masyarakat pada umumnya. Pemasaran jasa merupakan proses sosial dimana individu dan kelompok mendapatkan apa yang mereka butuhkan dan inginkan dengan mempertukarkan jasa yang bernilai. Dilihat dari segi manajemen, manajemen pemasaran merupakan kegiatan penganalisisan perencanaan, pelaksanaan, dan pengendalian program yang disusun untuk membangun keuntungan dari pertukaran pasar berupa barang atau jasa (Atmoko 2018).

Adapun pengertian pemasaran menurut beberapa para ahli diantaranya sebagai berikut:

a. Menurut Philip Kotler

Pemasaran adalah kegiatan manusia yang diarah pada usaha untuk memuaskan keinginan dan kebutuhan me lalui proses pertukaran.

b. Menurut The American Marketing Association

Pemasaran adalah suatu ke giatan usaha yang meng arahkan aliran barang dan jasa kepada konsumen atau pemakai.

c. Menurut William j. Stanton

Pemasaran adalah sistem keseluruhan dari kegiatan usaha yang ditujukan untuk merencanakan, menentukan harga, mempromosikan dan mendistribusikan barang dan jasa yang dapat memuaskan kebutuhan pembeli yang ada maupun pembeli potensial.

Dari definisi-definisi tersebut da pat diambil kesimpulan sementa ra, bahwa pemasaran merupakan interaksi yang ber usaha men ciptakan hubungan pertukaran. 
Dengan demikian pemasaran dilakukan sebelum maupun se sudah terjadinya proses per tukaran demi tercipta nya kepuasan baik pembeli maupun penjual (Winarto 2011).

\section{B. Pengertian Strategi Pemasaran}

Strategi pemasaran adalah alat untuk mencapai tujuan pemasaran yang merupakan suatu cara bagaimana sebuah perusahaan dapat merebut mind share pelanggan. Dimensi strategi pemasaran terdiri dari tiga macam, yaitu :

a. Segmentasi Pasar (Segmentation)

Pasar merupakan sekumpulan individu yang dapat dijadikan sebagai konsumen dari produk yang dijual. Konsumen dapat dilihat dari umur, jenis kelamin, kelas sosial, latar belakang sosial budaya, dan gaya hidup yang berbeda. Dengan keadaan yang heterogen tersebut memungkinkan pihak perusahaan untuk memilah kelompok konsumen berdasarkan consumer behavioral characteristics. Dengan kata lain perusahaan melakukan suatu kegiatan yang disebut segmentasi.

Segmentasi pasar sebagai tindakan untuk membagi sebuah pasar keseluruhan suatu produk atau jasa yang bersifat heterogen ke dalam beberapa segmen, dimana masingmasing segmennya cenderung bersifat homogen dalam segala aspek dan dapat dipilih sebagai target pasar untuk dicapai perusahaan dengan strategi pemasarannya. Segmentasi yang berhasil memiliki arti memuaskan kebutuhan pelanggan yang sudah ada dan pelanggan potensial dalam pasar yang ditetapkan dengan jelas. Ini melibatkan pemahaman atas sikap pelanggan, dan preferensi pelanggan, dan juga manfaatmanfaat yang dicari. Definisi pasar sasaran dan permintaannya merupakan langkah pertama yang penting dalam proses segmentasi.

b. Pasar Target (Targeting)

David W. Cravens mengatakan bahwa penetapan pasar sasaran artinya memilih konsumen atau organisasi yang akan dilayani manajemen dalam pasar produk. Strategi ini dipengaruhi oleh kematangan pasar, keanekaragaman kebutuhan dan preferensi pembeli, ukuran perusahaan dibanding pesaingnya, sumber daya dan prioritas perusahaan, serta besarnya pasar yang diperlukan untuk mencapai keadaan keuangan yang menguntungkan. 


\section{c. Positioning}

Posisi yang diinginkan oleh suatu perusahaan terhadap apa yang ada di benak konsumen (Budiarto 2013). 


\section{BAB III \\ PENUTUP}

\section{A. Kesimpulan}

Dari penjelasan pembahasan pada bab sebelumnya maka dapat ditarik kesimpulan bahwa Strategi adalah keseluruhan konsep bagaimana sebuah perusahaan mengatur dirinya sendiri dan semua kegiatan dengan tujuan agar bisnis yang dijalankan berhasil, melakukan persaingan, dan melakukan imbal hasil kepada pemegang saham 


\section{DAFTAR PUSTAKA}

Atmoko, T. Prasetyo Hadi. "Strategi Pemasaran Untuk Meningkatkan Volume Penjualan di." Journal of Indonesian Tourism, Hospitality and Recreation 1, no. 2 (2018): 83-96.

Budiarto, Samsul. "Strategi Pemasaran Dengan Menggunakan Pendekatan Mark Plus \& Co Di Kandatel Jakarta." INDEPT 3, no. 1 (2013): 13-24.

Winarto, Hari. "Strategi Pemasaran." Majalah Ilmiah Ekonomi 14, no. 3 (2011): 109-145. 